\title{
PERANCANGAN APLIKASI PENGOLAHAN DATA PROYEK PERUSAHAAN KONTRAKTOR GUNASLAND BEKASI BERBASIS JAVA NETBEANS
}

\author{
Rizky Kurniawa ${ }^{1}$, Fitriana Destiawati ${ }^{2}$, Intan Vandini ${ }^{3}$ \\ 1,2,3 Universitas Indraprasta PGRI \\ Jalan Raya Tengah No.80, Kelurahan Gedong, Pasar Rebo, Jakarta Timur \\ 1.rizkur4566@gmail.com, ${ }^{2}$ honeyzone86@gmail.com, ${ }^{3}$ Intanvandini25@gmail.com
}

\begin{abstract}
ABSTRAK
Gunasland Bekasi adalah perusahaan didalam bidang kontraktor dalam pengembangan real estate yang beroperasi di Jakarta, Bekasi dan Jambi. Gunasland Bekasi juga memberikan penekanan kuat pada kehidupan rumah ramah lingkungan dengan terus meninjau tren dan teknologi baru dalam pengemabangan pembangunan hijau. Sebagai bagian dari apresiasi terhadap budaya Indonesia. Gunasland Bekasi sendiri belum memiliki aplikasi pengolahan data yang mana dalam pencarian datanya berupa file berkas dan proses laporan masih berupa dokumen. Tujuan penelitian ini dilakukan adalah untuk mengatasi sistem pengolahan data proyek yang ada, dimana sistem yang digunakan masih ada kekurangan dan belum optimal dan juga untuk merancang sebuah aplikasi yang dapat mempermudah segala sesuatu yang berhubungan dengan pengolahan data proyek perusahaan dan agar atasan dapat mengakses langsung data pada aplikasi, Seperti mudah hilang dan sulitnya dalam pencarian data. Metode penelitian yang digunakan adalah metode deskriptif Dapat dikatakan bahwa penelitian deskriptif merupakan penelitian yang berusaha mendeskripsikan suatu gejala, peristiwa yang terjadi pada saat sekarang atau masalah aktual. Berdasarkan metode tersebut pengumpulan data yang dilakukan memperoleh hasil data yang akurat. Hasil dari penelitian ini adalah sebuah aplikasi sistem informasi pengolahan data proyek yang sudah terkomputerisasi agar membuat pekerjaan menjadi lebih efektif lagi, terdata lebih baik dan tersimpan lebih aman.
\end{abstract}

Kata Kunci: Perancangan, Pengolahan Data Proyek, Berbasis Java Netbean

\begin{abstract}
Gunasland Bekasi is a contractor company in real estate development that operates in Jakarta, Bekasi and Jambi. Gunasland Bekasi also places a strong emphasis on eco-friendly home living by continuously reviewing new trends and technologies in the development of green development. As part of the appreciation of Indonesian culture. Gunasland Bekasi itself does not have a data processing application where the data search is in the form of files and the report process is still in the form of documents. The purpose of this research is to overcome the existing project data processing system, where the system used is still lacking and not optimal and also to design an application that can simplify everything related to the company's project data processing and so that superiors can access data directly on the project. applications, such as easy to lose and difficult to find data. The research method used is descriptive method. It can be said that descriptive research is research that seeks to describe a symptom, an event that occurs at the present time or an actual problem. Based on this method, data collection was carried out to obtain accurate data results. The result of this research is an application of a computerized project data processing information system in order to make work more effective, better recorded and stored more securely.
\end{abstract}

Key Word: Design, Project Data Processing, Java Netbean Based

\section{PENDAHULUAN}

Perkembangan zaman saat ini sangatlah luarbiasa perkembangannya, banyak yang sudah menggunakan teknologi yang maju dengan menggunakan alat bantu komputer. Pada saat ini perusahaan tidak hanya dipaksa untuk menerapkan strategi produk atau harga saja namun juga dituntut untuk mengelola informasi yang akurat sehingga pihak managerial dapat mengambil kebijakan yang sesuai dalam menyelesaikan suatu masalah atau menetapkan rencana yang berkaitan dengan kegiatan operasional atau untuk memenuhi goal/tujuan tertentu. Perusahaan Gunasland Bekasi dalam pengembangan perusahaan real estatenya terdapat di Jakarta, Bekasi dan Jambi. Gunasland Bekasi sangat memerhatikan alam sekitar yang mana memberikan kebijakan kuat pada pembangunan hijau ramah lingkungan dengan terus meerhatikan teknolgi dan trend baru dalam pembangunan yang eco-firendly.

808 | Perancangan Aplikasi Pengolahan Data Proyek Perusahaan Kontraktor Gunasland Bekasi Berbasis Java Netbeans 
Tertuju untuk mengapresiasi terhadap budaya Indonesia.

Permasalahan yang terdapat pada perusahaan Gunasland Bekasi tersebut yaitu walaupun dalam pendataan sudah terkomputerisasi tetapi masih berupa file - file yang tidak tersusun, mudah hilang dan sulit nya dalam pencarian data. Berdasarkan permasalahan tersebut untuk itu alasan penulis merancang untuk membuat aplikasi desktop yang berbasis java netbean, selaku peneliti aplikasi itu diharapkan dapat membantu karyawan untuk membuat laporan yang lebih efektif, efisien dan akurat kepada atasan perusahaan.

Penelitian yang relevan berasal dari penelitian dengan judul "Rancang Bangun Sistem Informasi Pengolahan Data Ternak Di Perusahaan Dagang Perusahaan Pengengembangan Usaha Ternak Indonesia (PD. PPUTI)" (Maulana \& Fitriani, 2016). Dengan adanya sistem tersebut, Sistem Informasi yang dirancang membuat proses pengolahan data ternak menjadi lebih efektif dan efisien baik dalam segi waktu maupun biaya.

Penelitian serupa lainnya berjudul "Sistem Informasi Pengolahan Data Pelaporan Pengawasan Perusahaan" (Amelia, 2020). Dengan menggunakan Sistem Informasi pengolahan data pelaporan pengawasan perusahaan mempermudah pengawas dalam mendata perusahaan-perusahaan yang ada dilingkup provinsi sumatera barat, memudahkan pencarian data perusahaan dan memudahkan pimpinan dalam mengambil keputusan. Dari kesimpulan dari dua penelitian yang relevan ini, peneliti implementasikan terhadap perusahaan Gunasland Bekasi dengan tujuan merancang sebuah aplikasi yang dapat mempermudah segala sesuatu yang berhubungan dengan pengolahan data proyek perusahaan dan agar atasan dapat mengakses langusng data pada aplikasi.

\section{METODE PENELITIAN}

Metode penelitian adalah cara utama yang digunakan peneliti untuk mencapai tujuan dan menentukan jawaban atas masalah yang diajukan (Arikunto, 2019). Metode penelitian diartikan sebagai cara ilmiah ntuk mendapatkan data yang valid dengan tujuan dapat ditemukan, dikembangkan, dan dibuktikan, suatu pengetahuan tertentu sehingga pada giliranya dapat digunakan untuk memahami, memecahkan, dan mengantisipasi masalah (Sugiono, 2015). Metode penelitian deskriptif adalah suatu penelitian yang dilakukan untuk mengetahui nilai variabel mandiri, baik satu variabel atau lebih (independen) tanpa membuat perbandingan atau menghubungkan dengan variabel lain. Artinya penelitian ini hanya ingin mengetahui bagaimana keadaan variabel itu sendiri tanpa ada pengaruh atau hubungan terhadap variabel lain seperti penelitian eksperimen atau korelasi (Sugiyono, 2018). Berdasarkan penjelasan diatas dapat diartikan bahwa metode penelitian adalah suatu proses atau langkah dalam mencari dan mendapatkan data pada penelitian tertentu dengan cara ilmiah dengan bertujuan untuk suatu keperluan dan kegunaan tertentu. Metode penelitian yang dipakai dalam penelitian ini yaitu metode deskriptif. Dapat dikatakan bahwa penelitian deskriptif adalah penelitian yang berupaya mendeskripsikan suatu gejala, peristiwa yang terjadi pada saat ini atau masalah yang sebenarnya. Penelitian ini bertempat di Perusahaan Gunasland Bekasi yang berlokasi Jl. Raya Narogong, RT.002/RW.005, Bantargebang, Kota Bekasi, Jawa Barat 17151.

Berdasarkan metode tersebut pengumpulan data yang dilakukan memperoleh hasil data yang akurat. Metode pengembangan sistem yang digunakan adalah metode waterfall dengan tahapan sebagai berikut :

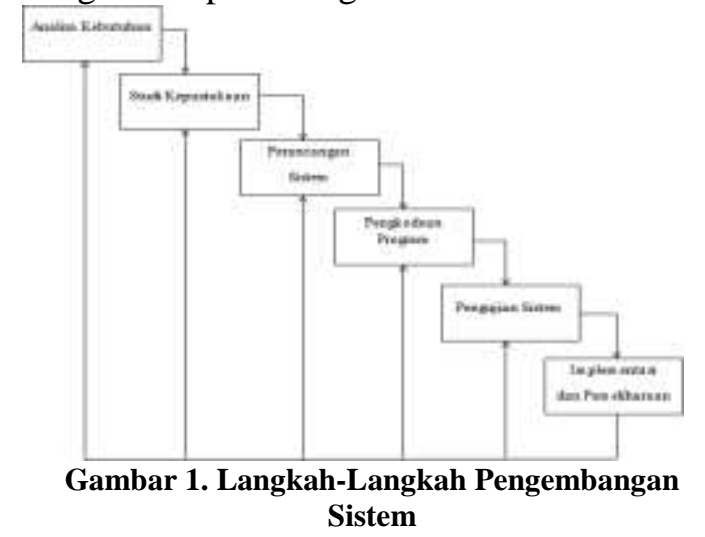

809 | Perancangan Aplikasi Pengolahan Data Proyek Perusahaan Kontraktor Gunasland Bekasi Berbasis Java Netbeans 


\section{HASIL DAN PEMBAHASAN}

\section{Analisis Permasalahan}

Dari hasil penelitian yang telah di lakukan maka peneliti dapat menganalisa permasalahan yang terdapat pada pengelolaan pendataan jasa perusahaan kontraktor Gunas Land antara lain :

1. Belum adanya aplikasi khusus perusahaan untuk melihat data pengelolaan proyek, untuk melihat daftar-daftar proyek mana saja yang sedang berjalan maupun sudah selesai.

2. Penyimpanan data yang kurang efektif menyebabkan data tertumpuk rapih dan memerlukan waktu yang untuk melakukan pencarian data kembali dan menyebabkan terjadinya masalah pada pembuatan laporan.

3. Kurang praktisnya pembuatan laporan data proyek, data pelanggan dan data karyawan

4. Resiko hilang dan rusaknya dokumen

\section{Aturan Bisnis Diusulkan}

Aturan bisnis system informasi pengelolaan data proyek yang diusulkan pada Gunas Land Bekasi adalah sebagai berikut :

1. Admin perusahaan akan mendaftarkan karyawan atau pegawai agar dapat mengakses aplikasi perusahaan.

2. Admin perusahaan memasukan data diri karyawan lalu memberikan id dan kata sandi kepada karyawan tersebut agar dapat mengakses aplikasi perusahaan.

3. Bagian admin akan mengecek data proyek yang sedang bejalan maupun proyek yang sudah selesai dengan menginput data karyawan, data proyek dan data pelanggan.

4. Manager proyek akan memberikan laporan proyek berupa data proyek yang sedang berjalan maupun yang sudah selesai kepada admin untuk peng-inputan ke aplikasi.

5. Bagian admin akan melakukan rekap data pemasukan dan pengeluaran, serta kegiatan proyek perbulannya untuk dijadikan laporan.

6. Laporan data perbulan akan diserahkan kepada direktur perusahaan secara berkala.

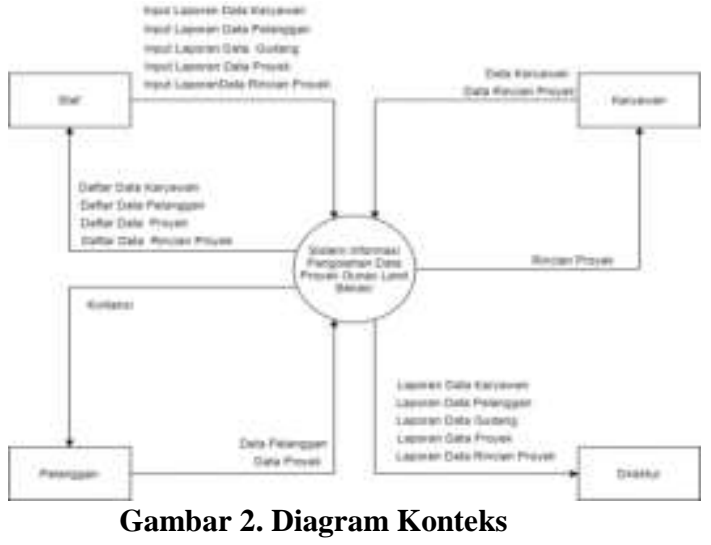

Gambar diatas adalah gambar diagram konteks yang diusulkan untuk perusahaan.

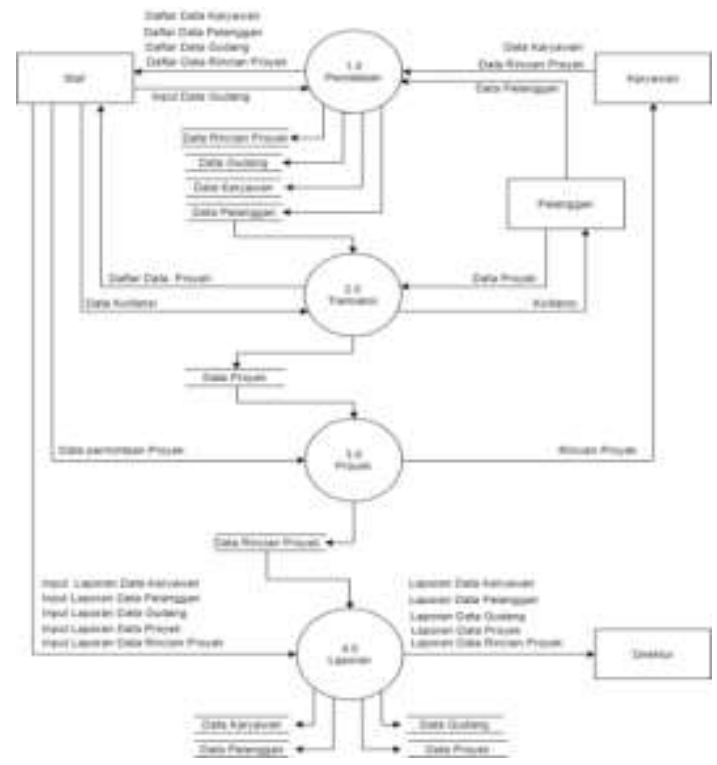

Gambar 3. Diagram Nol

Gambar diatas adalah gambar diagram nol yang menjelaskan seluruh alur dari sistem perusahaan, mulai dari sistem pendataan dimana staf akan menginput data karyawan, pelanggan, gudang, proyek dan rincian proyek lalu disinpan ke dalam database. Kemudian proses Transaksi yaitu proses dimana pelanggan memberikan permintaan proyek. Selanjut ada proses proyek dimana data permintaan proyek diolah oleh karyawan (divisi proyek). Proses yang terakhir adalah laporan yaitu dimana staf menginput seluruh laporan berupa laporan data karyawan, pelanggan, gudang, proyek dan rincian proyek kepada direktur.

\section{Normalisasi}

Normalisasi merupakan tahapan pengelompokan komponen data yang menjadi tabel-tabel yang mennunjukan 
entitas suatu relasi (Mahendra \& Eby Yanto, 2018). Normalisasi adalah teknik dengan melakukan sebuah pendekatan bottom-up yang digunakan dalam membantu mengidentifikasikan hubungan. (Indrajani, 2015). Normalisasi merupakan sebuah upaya untuk mendapatkan basis data dengan struktur yang baik, terutama sekali untuk efesiensi ruang penyimpanan (storage) (Lubis, 2016).

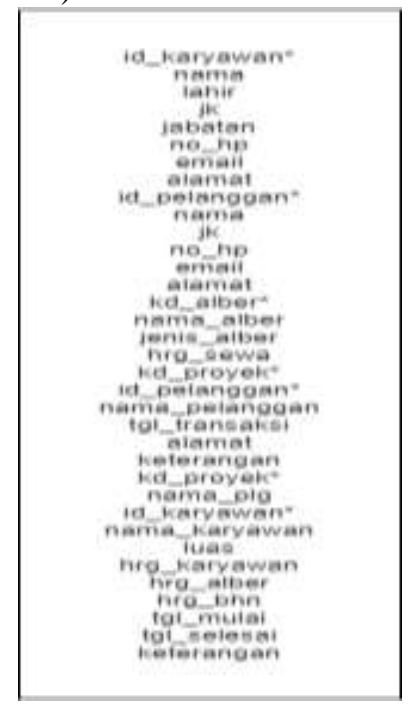

Gambar 4. Normalisasi Tidak Normal
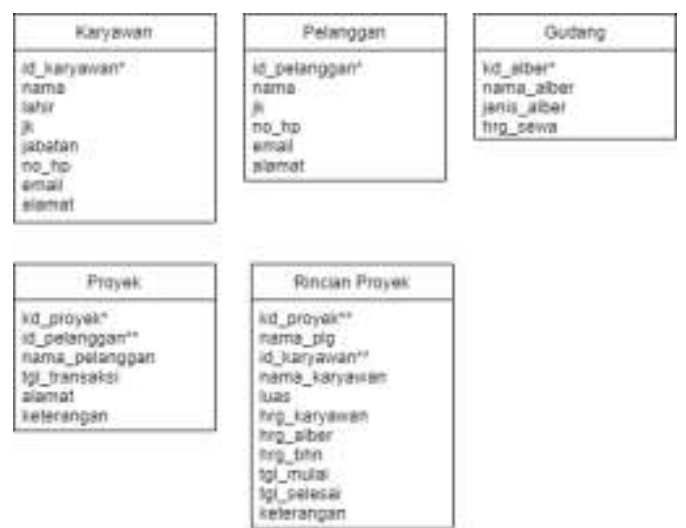

Gambar 5. Normalisasi 1NF

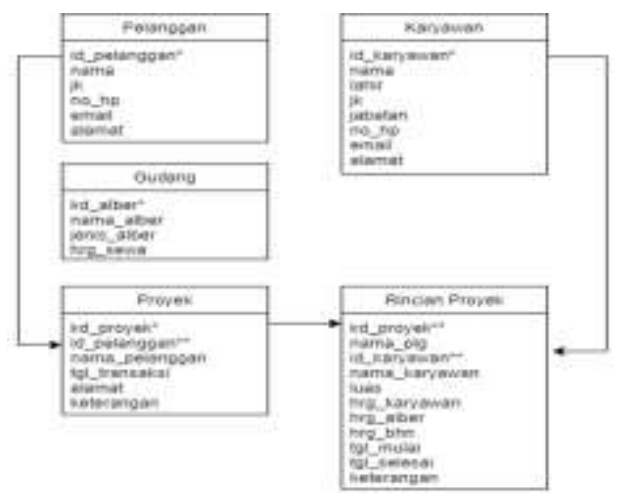

Gambar 4. Normalisasi 2NF
ERD (Entitiy Relationship Diagram)

ERD adalah bentuk paling awal dalam melakukan perancangan basis data relasional. Jika menggunakan OODMBS maka perancangan ERD tidak perlu dilakukan (Rosa \& Shalahuddin, 2015) Entity Relationship Diagram (ERD) adalah suatu model jaringan yang menggunakan susunan data yang disimpan dalam sistem secara abstrak (Ladjamudin, 2016).

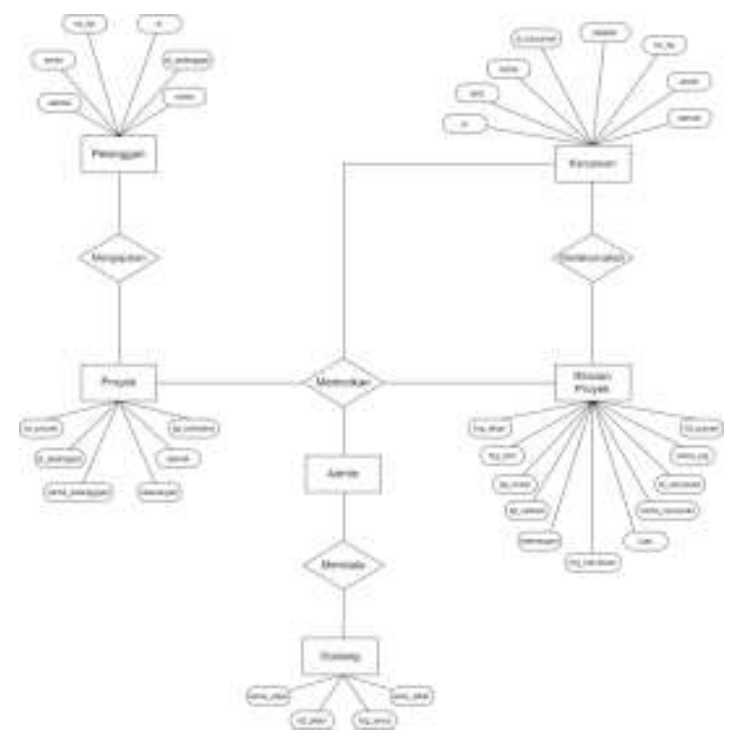

Gambar 5. ERD (Entity Relatonship diagram)

Normalisasi

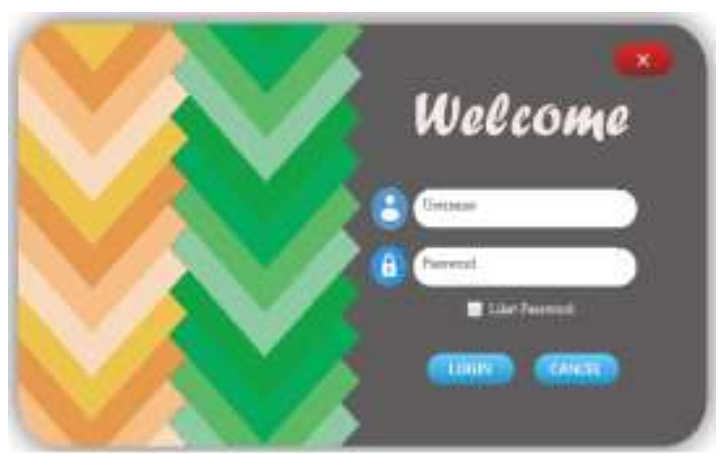

Gambar 6. Tampilan Layar Menu Login

Pada halaman ini akan muncul menu login pada awal dimana saat membuka program. Pada halaman tersebut admin diharuskan untuk memasukkan use rname dan password yang sesuai spaya admin dapat mengakses dan dapat mengoperasikan sistem. Jika username dan password sesuai, maka akan masuk kepada tampilan selanjutnya atau halaman menu utama.

811 | Perancangan Aplikasi Pengolahan Data Proyek Perusahaan Kontraktor Gunasland Bekasi Berbasis Java Netbeans 


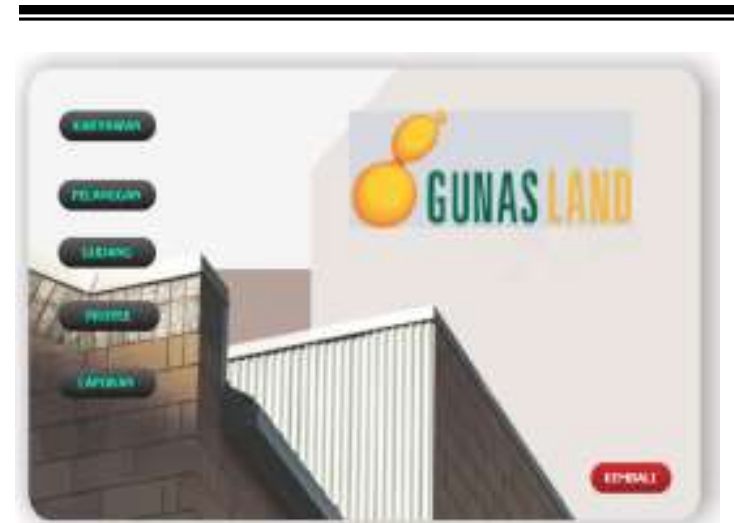

Gambar 7. Tampilan Layar Menu Utama

Pada halaman menu utama ini mwmiliki beberapa button (tombol) yang dapat diklik sehingga menampilkan halamanhalaman baru baru untuk proses input selanjutnya.

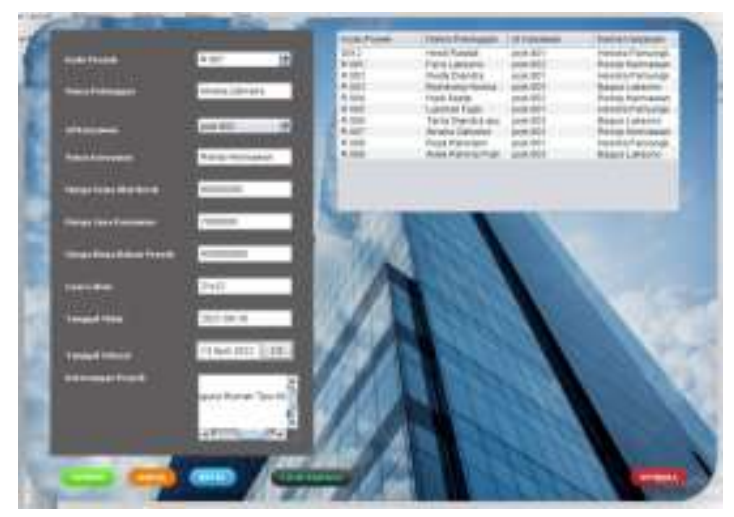

Gambar 8. Tampilan Layar Menu Rincian Proyek

Pada halaman rincian proyek ini, user dapat melakukan penambahan data rincian proyek, mengubah, dan menghapus data rincian proyek. Tekan tombol (simpan) untuk menyimpan data dan untuk mengubah atau mengupdate, lalu untuk menghapus data klik tombol (hapus). Pilih tombol (batal) apabila ingin mereset data pada textfield dan tekan tombol cetak kwitansi untuk mencetak kwitansi bukti pembayaran.

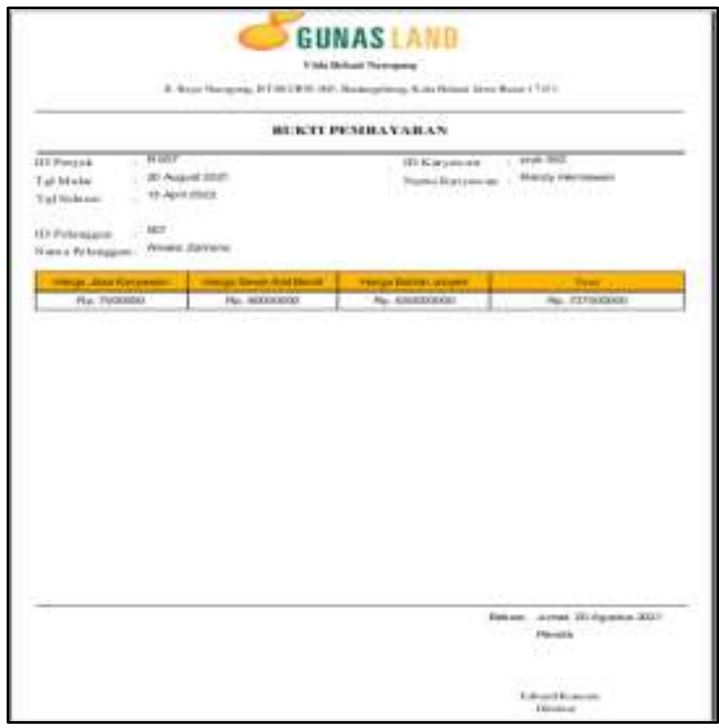

Gambar 9. Tampilan Laporan Kwitansi Pelanggan

Tampilan diatas adalah lembar gambar kwitansi pembayaran yang akan diterima oleh pelanggan.

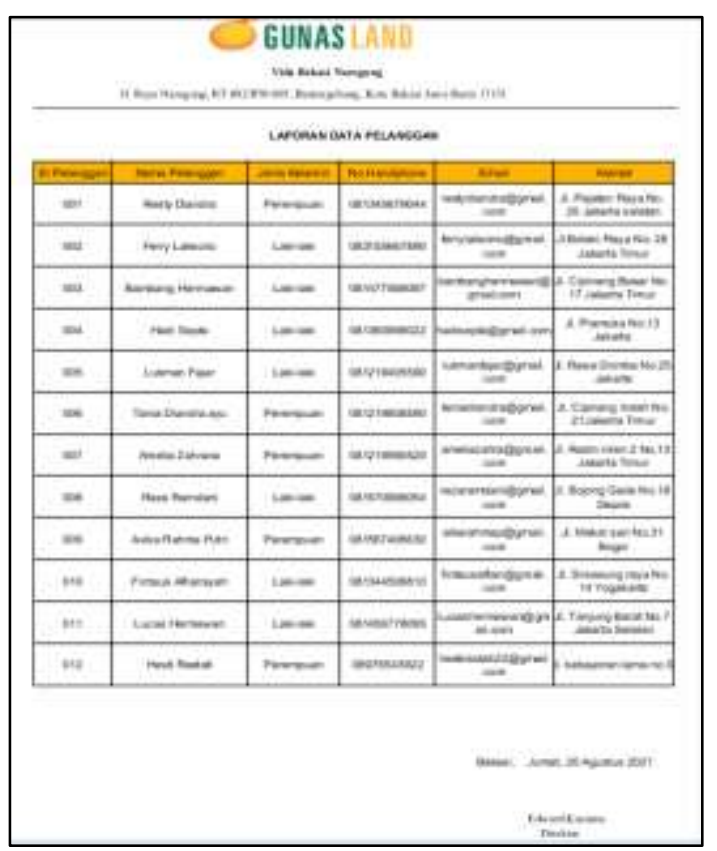

Gambar 10. Tampilan Laporan Kwitansi Pelanggan

Tampilan diatas adalah lembar gambar Laporan data pelanggan yang akan dikirimkan kepada direktur 


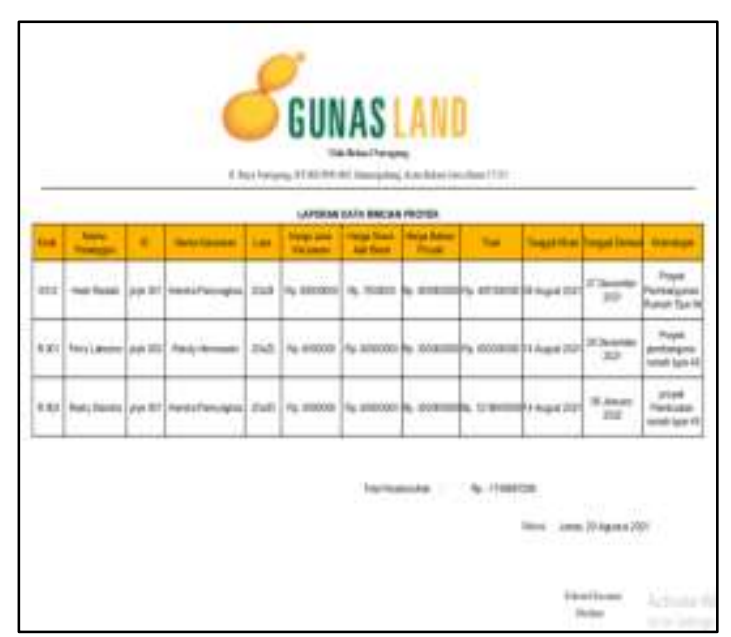

Gambar 11. Tampilan Laporan rincian proyek

Tampilan diatas adalah lembar gambar Laporan data rincian proyek yang akan dikirimkan kepada direktur.

\section{SIMPULAN DAN SARAN}

Setelah melakukan penelitian serta perancangan pembuatan aplikasi, penulis dapat menarik kesimpulan bahwa dengan membangun Perancangan Aplikasi Pengolahan Data Proyek Perusahaan Kontraktor Gunasland Bekasi Berbasis Java Netbean, dapat disimpulkan diantaranya sebagai berikut :

Dengan adanya rancangan sistem ini, dapat lebih memudahkan proses pendataan sehingga lebih membantu dalam menangani proses penginputan data, sehingga dapat mengurangi terjadinya kesalahan pada penginputan data dari sistem yang sudah ada sebelumnya. Sistem ini berhubungan dengan pendataan dan pembayaran yang akan disimpan secara terkomputerisasi pada penyimpana database sehingga dapat melakukan pencarian data dengan mudah. Penggunaan sistem ini mempermudah dalam pembuatan laporan, karena sistem ini tidak terlalu sulit digunakan sehingga user dapat melakukan pembuatan laporan dengan mudah dan cepat.

Penulis memberikan saran agar dapat menunjang kemajuan Perusahaan Gunasland dalam menggunakan sistem sesuai dengan kesimpulan penulis dan apa yang telah penulis alami dengan proses penelitian pada Perusahaan Gunasland Bekasi. Berikut ini saran-saran yang dapat penulis uraikan diantaranya sebagai berikut :
Sebelum sistem baru diterapkan, sebaiknya pihak Perusahaan harus diberikan penjelasan dengan baik terlebih dahulu mengenai proses kerja sistem yang akan diterapkan sehingga tidak terjadi kekeliruan. Walaupun data sudah tersimpan di database, Keamanan sistem perlu dijaga dengan cara mempercayakan sistem kepada staff yang berwenang dan bertanggung. jawab. Ketelitian dalam penginputan data perlu diperhatikan agar seluruh data yang akan dimasukan ke dalam database benar-benar merupakan data asli dari seluruh data perusahaan.

Pada penelitian mendatang dengan perkembangan informasi dan teknologi yang sangat cepat, penulis mengharapkan sistem perancangan pengolahan data perusahaan dapat diakses secara online dan lebih dikembangkan lagi.

Dengan demikian saran yang dapat penulis berikan, semoga saran tersebut dapat dijadikan suatu masukan yang bermanfaat kepada pihak yang terkait dan bagi penulis khususnya dalam melakukan pengembangan pada penelitian selanjutnya.

\section{DAFTAR PUSTAKA}

Amelia, D. (2020). Sistem Informasi Pengolahan Data Pelaporan Pengawasan Perusahaan. J-Click, 6(2), 201-207.

Arikunto. (2019). Metodelogi Penelitian, Suatu Pengantar Pendidikan. In Rineka Cipta, Jakarta.

Indrajani, I. (2015). Analisis dan Penerapan Metode Tuning pada Basis Data Funding. ComTech: Computer, Mathematics and Engineering Applications, 6(1). https://doi.org/10.21512/comtech.v6i1.2 299

Ladjamudin. (2016). Migrasi dan Optimalisasi Database Sistem Informasi berbasis E-Learning Program Diploma III Manajemen Informatika Universitas Muhammadiyah Metro. MIKROTIK: Jurnal Manajemen Informatika, 6(2).

Lubis, A. (2016). Perancangan Sistem Informasi Usaha Ekonomi Kelurahan Simpan Pinjam (UEK-SP)Mekar Sari Pada Lembaga Pemberdayaan Kelurahan Rejosari Pekanbaru Berbasis Web. Riau Journal of Computer 
Science, 2(1).

Mahendra, I., \& Eby Yanto, D. T. (2018).

Sistem Informasi Pengajuan Kredit

Berbasis Web Menggunakan Agile

Development Methods Pada Bank Bri

Unit Kolonel Sugiono. Jurnal Teknologi

Dan Open Source, 1(2).

https://doi.org/10.36378/jtos.v1i2.20

Maulana, A. I., \& Fitriani, L. (2016).

Pengolahan Data Ternak Di Perusahaan Dagang Perusahaan Pengengembangan Usaha Ternak Indonesia. Jurnal Algoritma Sekolah Tinggi Teknologi Garut, 13 No. 1, 315-319. http://sttgarut.ac.id/jurnal/index.php/alg oritma/article/view/365

Rosa, \& Shalahuddin. (2015). Komponen ERD. In Sebuah ERD tersusun atas tiga komponen, yaitu entitas, atribut, dan kerelasian antar entitas. Secara garis besar, entitas merupakan obyek dasar yang terlibat dalam sistem. Atribut berperan sebagai penjelas entitas, sedangkan kerelasian menunjukkan hubunga.

Sugiono, S. (2015). Deskripsi Tentang Minat Karir Menurut Teori Hollandpada Siswa Kelas Xiisma Prasetya Kota Gorontalo. Skripsi.

Sugiyono. (2018). Prof. Dr. Sugiyono. 2018. Metode Penelitian Kuantitatif, Kualitatif, dan R\&D. Bandung: Alfabeta. Prof. Dr. Sugiyono. 2018. Metode Penelitian Kuantitatif, Kualitatif, Dan R\&D. Bandung: Alfabeta. 